\title{
kinhtế:dulịch
}

$05 / 10 / 202111: 30$

\section{Quy hoạch di sản: Một góc nhìn từ Hội An}

Năm 1999, phố cổ Hội An của Việt Nam được UNESCO công nhận là Di sản Văn hóa thế giới. Kể tù thời điểm đó, bộ mặt thành phố Hội An đã có nhiều thay đổi, biến nơi đây trở thành một điểm đến hấp dẫn khách du lịch trong và ngoài nước. Nhiều chính sách quy hoạch đã được đưa ra nhằm thúc đẩy phát triển du lịch và kinh tế. Tuy nhiên, yếu tố bảo tồn và phát huy di sản cần phải được chú trọng hơn nũa để có gìn giữ trọn vẹn nhũng giá trị truyền thống của Hội An.

Là một trong những Di sản thế giới được UNESCO công nhận tại Việt Nam, Hội An được nhiều chuyên gia đánh giá là một "điển hình thành công” trong công tác bảo tồn di sản ở khu vực Đông Nam Á. Ngoài việc được trao tặng những giải thưởng uy tín từ các tổ chức quốc tế, Hội An còn chứng kiến lượng khách du lịch tăng gấp 16 lần trong giai đoạn từ 1997 đến 2018, cùng với đó là nguồn doanh thu từ du lịch năm 2006 ước tính đạt 1 tỉ USD. Đây là những minh chứng rõ nét cho sự phát triển vượt bậc về kinh tế và du lịch của điểm đến di sản Hội An. Tuy nhiên, vẫn còn đó những mối lo về tính bền vững xã hội của di sản này, khi mà trong những năm trở lại đây, thành phần dân cư của Hội An đã có nhiều sự thay đổi, cùng với đó là nguy cơ vùng lõi di sản bị rơi vào trạng thái "bảo tàng hóa".

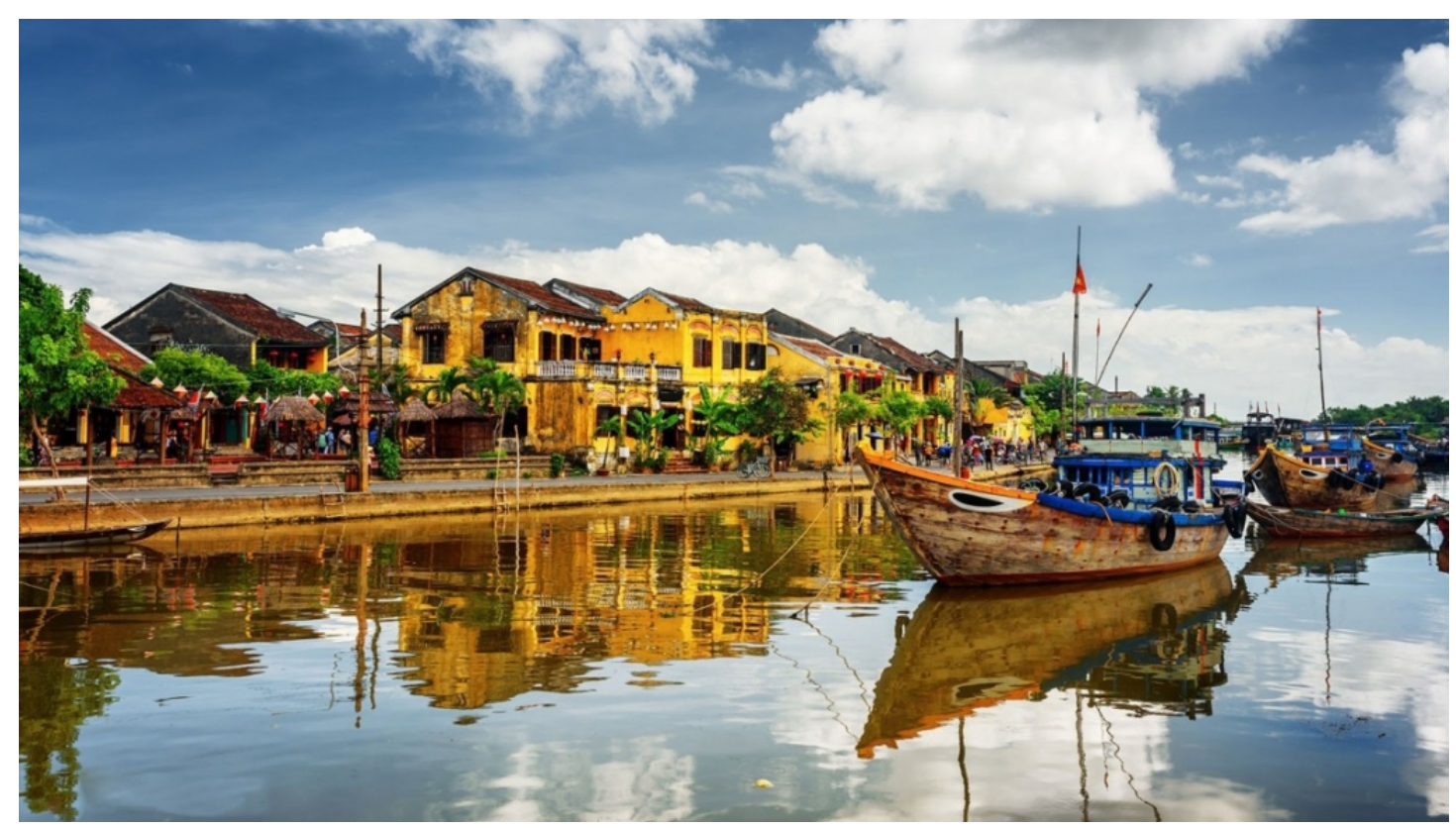

Năm 1999, phố cổ Hội An được UNESCO công nhận là Di sản Văn hóa thế giới Bằng việc phân tích xu hướng phát triển du lịch và Hội An cần có một chính sách dữ liệu nhân khẩu học của cư dân ở Hội An, đồng bảo tồn phù hợp. Việc tập trung thời theo dõi quá trình "bảo tàng hóa" khu vực vùng tái tạo khu vực vùng đệm cùng lõi và tái tạo vùng đệm di sản, nhóm tác giả Thomas với phát triển giá trị văn hóa bảo Jones, Bùi Thanh Hương (Ritsumeikan Asia Pacific 
University, Nhật Bản) và Katsuhiro Ando vệ môi trường trong cộng đồng là (Kamanashi Prefectural University, Nhật Bản) đã biện pháp khởi đầu hiệu quả để thực hiện nghiên cứu "Zoning for world heritage đảm bảo sự bền vững xã hội của sites: dual dilemmas in development and di sản Hội An trong tương lai. demographics" [1] nhằm đánh giá về sự bền vững xã hội dài hạn của di sản Hội An. Kết quả của nghiên cứu được đăng tải trên Tạp chí

\section{Tourism Geographies.}

Bài nghiên cứu được thực hiện bằng phương pháp hỗn hợp, dựa trên nhiều nguồn thông tin khác nhau như dữ liệu điều tra dân số, bản đồ, phỏng vấn và cả hướng dẫn quy hoạch không gian. Chính sự tổng hợp từ dữ liệu từ nhiều nguồn đa chiều này giúp cho nghiên cứu đem lại một góc nhìn toàn diện hơn về Hội An so với các nghiên cứu trước đây.

Dựa trên kết quả phân tích, nhóm tác giả đã đưa ra 3 kết luận đáng chú ý. Thứ nhất là sự xuất hiện của những xu hướng di dân đối nghịch giữa vùng lõi và vùng đệm di sản Hội An. Bản đồ nhân khẩu học từ năm 2001 cho đến năm 2010 cho thấy, tại khu vực phường Minh An - khu vực nằm trong vùng lõi di sản và được bảo tồn nghiêm ngặt chứng kiến sự suy giảm dân số lên tới $20 \%$. Ngược lại, trong cùng thời gian đó, số lượng dân cư tại hai phường Cẩm Châu và Cẩm Phô, 2 phường thuộc khu vực vùng đệm (là khu vực giáp ranh với vùng lõi và có chính sách bảo tồn ít nghiêm ngặt hơn) lại tăng tới hơn 10\%. Mặt khác, $80 \%$ dân số hiện nay tại vùng lõi di sản Hội An không phải là người bản địa. Họ chủ yếu tới từ những thành phố lớn như Hà Nội, Thành phố Hồ Chí Minh, hay Đà Nẵng, sau đó thuê hoặc mua đất trong vùng lõi, qua đó có đủ tư cách để trở thành cư dân chính thức của Hội An. Những người dân bản địa, theo chiều ngược lại, đã bán hoặc cho thuê nhà ở của cha ông họ để lại trong vùng lõi, sau đó di chuyển sang vùng đệm và định cư ở đây.

Thứ hai, hệ thống phân cấp vùng trong quy hoạch di sản tại Hội An chưa thật sự phù hợp với cấu trúc kinh tế xã hội của thành phố. Theo đó, khu vực di sản Hội An được chia thành 2 vùng: vùng lõi và vùng đệm. Vùng lõi có diện tích khoảng 30 ha, được đặt tên là "Vùng I" bởi chính quyền thành phố vào năm 2008, là khu vực được bảo tồn gần như nguyên vẹn. Vùng đêm là khu vực bao quanh vùng lõi, có diện tích lên tới 280 ha, và được chia thành hai khu vực nhỏ hơn là "Vùng IIA" và "Vùng IIB" để thuận tiện cho các mục đích bảo vệ sinh thái và cảnh quan. Tuy nhiên, diện tích của khu trung tâm Hội An vẫn là hơi nhỏ để có thể đáp ứng được nhu cầu sử dụng của một thành phố lịch sử - du lịch. Do đó, nhiều tòa nhà di sản trong vùng lõi buộc phải trở thành cửa hàng, quán cà phê, cửa hàng đồ lưu niệm... để phục vụ du khách, trong khi vẫn phải duy trì nguyên vẹn mặt tiền bằng gỗ để đáp ứng các quy tắc bảo tồn. Điều này tuy giúp gia tăng lợi ích kinh tế cho thành phố, song lại khiến cho vùng lõi di sản bị thương mại hóa và dần trở thành một "bảo tàng ngoài trời".

Cuối cùng, nhóm tác giả cho rằng, nên xem xét lại việc áp dụng phương pháp quy hoạch truyền thống bắt nguồn từ châu Âu cho các khu vực di sản đương đại. Phương pháp này chỉ tập trung chủ yếu vào việc bảo tồn các di sản vật thể. Điều này vô hình trung gây nên bất cập với sự bền vững xã hội ở Hội An. Chủ nhân các ngôi nhà cổ 
được khuyến khích rời khỏi vùng lõi để phục vụ việc bảo tồn nguyên trạng, cùng với đó là sự gia tăng lượng khách du lịch, khiến cho các tòa nhà ở đây bị chuyển mục đích sử dụng, từ sinh sống sang thành buôn bán hay phục vụ trưng bày. Vùng lõi Hội An vì thế mà mất đi sức sống và sự yên bình vốn có, thay vào đó là cảm giác về một "khu bảo tàng ngoài trời". Không những vậy, việc người dân bản địa rời khỏi khu vực trung tâm còn khiến nơi đây mất đi những giá trị truyền thống được gìn giữ bởi các gia đình đã sinh sống qua nhiều thế hệ. Việc quá tập trung vào bảo tồn một di sản vật thể lại vô tình làm lu mờ đi giá trị của một di sản phi vật thể khác.

Tuy tồn tại những hạn chế trong công tác bảo tồn, song chính quyền thành phố Hội An đã thực hiện những biện pháp tích cực để thúc đẩy sự bền vững xã hội của di sản. Tiêu biểu trong số đó là nỗ lực thu hút du khách tới tham quan các làng nghề ở vùng đệm thông qua các hoạt động văn hóa. Ở một vài làng nghề như làng mộc Kim Bồng hay làng gốm Thanh Hà, du khách được tạo cơ hội để trải nghiệm các hoạt động truyền thống của làng nghề trong thời gian lưu trú. Dù số lượng du khách ở khu vực vùng đệm vẫn chưa thể so sánh với lượt du khách ghé thăm vùng lõi, song những hoạt động như này sẽ giúp thu hút ngày càng nhiều du khách khám phá vùng đệm di sản, qua đó giúp tái tạo lại sức sống cho khu vực này. Trong bối cảnh Hội An vẫn cần có một chính sách bảo tồn phù hợp, việc tập trung tái tạo khu vực vùng đệm cùng với phát triển giá trị văn hóa bảo vệ môi trường trong cộng đồng [2,3] sẽ là một biện pháp khởi đầu hiệu quả để đảm bảo sự bền vững xã hội của di sản Hội An trong tương lai.

\section{Tham khảo:}

[1] Jones TE, Bui HT, \& Ando K. (2020). Zoning for world heritage sites: Dual dilemmas in development and demographics. Tourism Geographies, DOI: $10.1080 / 14616688.2020 .1780631$

[2] Vuong QH. (2021). The semiconducting principle of monetary and environmental values exchange. Economics and Business Letters, 9(3), 284-290, doi:10.17811/ebl.10.3.2021.284-290

[3] Ho MT. (2021). Gọi tên “giá trị văn hóa thứ 11". Kinh tế và Dự báo. URL: https://kinhtevadubao.vn/goi-ten-gia-tri-van-hoa-thu-11-18773.html

Trần Đức Hưng Long,

Ritsumeikan Asia Pacific University, Nhật Bản

Link nội dung: https://kinhtevadulich.vn/quyy-hoach-di-san-mot-goc-nhin-tu-hoi-ana83067.html 